\title{
PENGARUH KNEE TO CHEST DAN PELVIC TILTING EXERCISE TERHADAP FLEKSIBILITAS PUNGGUNG BAWAH PADA PEKERJA ADMINISTRASI DALAM AKTIVITAS DUDUK LAMA
}

\author{
The Effects of Knee-To-Chest and Pelvic Tilting Exercise on Lower Back Flexibility of \\ Administrative Officers Who Sit for A Long Period
}

\author{
Ifa Gerhanawati \\ Fisioterapi Universitas Muhammadiyah Surabaya
}

\section{Riwayat artikel \\ Diajukan: 21 Mei 2021 \\ Diterima: 13 Juli 2021}

\section{Penulis Korespondensi:}

- Ifa Gerhanawati

- Fisioterapi Universitas

Muhammadiyah

Surabaya

Email:

gerhanaifa@gmail.com

\section{Kata Kunci:}

Knee to Chest Exercise, Modified Schober Test, Pelvic Tilting Exercise

\begin{abstract}
Abstrak
Pendahuluan :. Penyebab sering duduk lama adalah adanya penggunaan otot yang berlebih saat tubuh mempertahankan posisi statis. Posisi statis ini disertai dengan postur yang salah, maka otototot daerah punggung akan bekerja lebih berat untuk mempertahankan posisi tubuh agar tetap tegak, akibatnya terjadi stress dan strain pada otot, tendon dan ligamen. Fleksibilitas dapat membuat tubuh lebih mudah dalam melakukan suatu gerakan dengan nyaman dan mencegah cedera serta perbaiki postur. Tujuan: membuktikan pengaruh pemberian knee to chest exercise dan pelvic tilting exercise terhadap fleksibilitas otot punggung bawah pada pekerja administrasi akibat aktivitas duduk lama. Metode subjek penelitian 30 orang wanita usia 25-35 tahun, jenis pekerjaan karyawan admimistrasi di Siloam Hospital Surabaya. subjek penelitian mempunyai gangguan fleksibilitas lumbal yang diukur dengan modified schober test (MST) dan Inclinometer sebelum dan setelah diberikan perlakuan. Metode penelitian quasi eksperimental kuantitatif dengan rumus Federer, terdapat 3 kelompok masing-masing 10 orang. kelompok 1 (K1) menggunakan pelvic tilting exercise, kelompok 2 (K2) menggunakan knee to chest exercise, dan kelompok 3 (K3) menggunakan knee to chest exercise dan pelvic tilting exercise. Data hasil penelitian dianalisis secara statik menggunakan program SPPS16. Hasil: uji bebas kelompok 1 Inclinometer $(\mathrm{p}=0,007)$ MST $(p=0,007)$, kelompok 2 Inclinometer $(\mathrm{p}=0,017)$ MST $(\mathrm{p}=0,002)$, kelompok 3 Inclinometer $(\mathrm{p}=0,000) \operatorname{MST}(\mathrm{p}=0,005)$, uji beda antar kelompok K1-K2 Inclinometer $(\mathrm{p}=0,516)$ MST $(\mathrm{p}=0,600), \mathrm{K} 1-\mathrm{K} 3$ Inclinometer $(\mathrm{p}=0,011)$ MST $(\mathrm{p}=0,056), \mathrm{K} 2-\mathrm{K} 3$ Inclinometer $(\mathrm{p}=0,003) \mathrm{MST}$ $(\mathrm{P}=0,014)$. Kesimpulan: knee to chest exercise dan pelvic tilting exercise sangat berpengaruh terhadap fleksibilitas otot punggung dibandingkan dengan melakukan salah satu saja latihan gerakan tersebut.
\end{abstract}

\section{Abstract}

Background: The cause of frequent long sitting is the use of excessive muscles when the body maintains a static position. This static position is accompanied by the wrong posture, then the back muscles will work harder to maintain an upright body position, resulting in stress or strain on the muscles, tendons and ligaments. Flexibility can make it easier for the body to perform a movement comfortably and prevent injury and improve posture. Decreased flexibility can affect muscle strength and endurance as well as neuromuscular control, resulting in a person not being able to perform functional movements.. Objective: to prove the effect of giving knee to chest exercise and pelvic tilting exercises on lower back muscle flexibility in administrative workers due to prolonged sitting activities Method the research subjects were 30 women aged 25-35 years with the type of work as administrative employees at Siloam Hospital Surabaya. All study subjects had impaired lumbar flexibility as measured by the modified schober test (MST) and inclinometer before and after treatment. The research method uses quantitative quasi-experimental with the Federer formula, there are 3 groups with each group consisting of 10 people. Treatment group 1 (K1) using pelvic tilting exercise, group 2 (K2) using knee to chest exercise, and group 3 (K3) using knee to chest exercise and pelvic tilting exercise. The research data were analyzed statically using the SPPS16 program. Results : independent test group 1 inclinometer $(\mathrm{p}=0.007)$ MST $(\mathrm{p}=0.007)$, group 2 inclinometer $(\mathrm{p}=0.017) \operatorname{MST}(\mathrm{p}=0.002)$, group 3 inclinometer $(\mathrm{p}=0.000)$ MST $(\mathrm{p}=0.005)$, test difference between groups $\mathrm{K} 1-\mathrm{K} 2$ Inclinometer $(\mathrm{p}=0,516) \mathrm{MST}(\mathrm{p}=0,600), \mathrm{K} 1-\mathrm{K} 3$ Inclinometer $(p=0,011)$ MST $(p=0,056), K 2-K 3$ Inclinometer $(p=0,003)$ MST $(P=0,014)$. Conclusion: knee to chest exercise and pelvic tilting exercise greatly affect the flexibility of the back muscles compared to doing just one of these movement exercises. 


\section{PENDAHULUAN}

Duduk dalam waktu lama dapat menyebabkan rasa tidak nyaman, sehingga menimbulkan nyeri pada punggung bawah. Aktivitas duduk lama ini sering dilakukan pada pekerja administrasi yang bekerja dengan posisi duduk dalam waktu lebih dari 6 jam (Weitz, 2005). Akibat aktivitas tersebut, para pekerja administrasi mengeluhkan nyeri pada bagian punggung bawah. Nyeri pada daerah punggung bawah disebabkan penggunaan otot yang berlebih atau akibat trauma yang menimbulkan stress atau strain pada otot, tendon, dan ligamen (Baehr, 2010). Menurut Chekin (2001), kejadian nyeri punggung bawah tergolong tinggi, prevalensi sebesar 50\%-80\% penduduk mengalami keluhan ini yang dapat menurunkan produktivitas kerja, sehingga diperkirakan persentase kejadian nyeri punggung bawah akan meningkat dengan bertambahnya usia. Berdasarkan penelitian Purba, dan Ashwin (2006) yang dilakukan pada 742 orang sampel yang berobat di poliklinik Neurologi RSCM selama bulan Mei 2002, diketahui bahwa 742 orang pengunjung poliklinik, ditemukan 116 orang penderita NPB dengan persentase 15,6\%. Dari jumlah ini 76 di antaranya mewakili kelompok jenis kelamin wanita proporsi $65,5 \%$ dan penderita pria terdiri dari 40 orang 34,5\% (Pubra, et al., 2006). Penggunaan otot yang berlebihan terjadi saat tubuh mempertahankan. posisi statis dalam waktu lama. Jika posisi dengan postur salah, maka otot-otot daerah punggung akan bekerja lebih berat untuk mempertahankan posisi tubuh agar tetap tegak (Sidharta, 2010). Pertahanan posisi ini dapat menimbulkan spasme pada otot punggung bawah yang terjadi dapat membatasi mobilitas lumbal terutama saat gerakan membungkuk (fleksi) dan memutar (rotasi). Apabila hal ini berlangsung lama dapat menyebabkan fleksibilitas sendi menurun (Kisner, 2011). Fleksibilitas penting untuk membuat tubuh lebih mudah dalam melakukan suatu gerakan dengan nyaman dan berguna agar tidak terjadi cedera dan dapat memperbaiki postur (William, 2006; dan Catherin, 2008). Pengukuran fleksibilitas menggunakan modified schober test (MST) dan Inclinometer (Purnama, 2007; dan MacDemid, 2014).

Fleksibilitas sendi berkurang dapat diperbaiki melalui beberapa cara, yaitu dengan massage, ultrasound diathermy (USD), exercise berupa streching aktif dan pasif, propioseptive neuromuscular fascilitation (PNF) dan William flexion (AAHPERD, 1999).

William Flexion Exercise merupakan salah satu jenis latihan yang digunakan untuk mengurangi nyeri pada punggung bawah dengan cara memperkuat otot-otot fleksor lumbo sacral, terutama otot abdominal dan otot gluteus maksimus dan ekstensor punggung bawah (Kusuma dan Setiowati, 2015). Latihan yang spesifik dibutuhkan untuk fleksibilitas pada punggung bawah, pada latihan William Flexion Exercise adalah gerakan pelvic tilting exercise dan knee to chest exercise, karena cenderung memiliki daya renggang yang cukup besar pada area lumbal dan koreksi postur pada lumbal dan pelvic (Kisner, 2011,\& Muscolino 2015). Tujuan penelitian adalah pengaruh gerakan pelvic tilting exercise dan knee to chest exercise terhadap fleksibilitas pada pekerja administrasi yang melakukan aktivitas dalam posisi duduk lama agar dapat meningkatkan ketahanan melakukan aktivitas dalam posisi duduk lama.

\section{METODE}

Subjek penelitian berjumlah 30 orang dengan kriteria inklusi adalah wanita usia 25-35 tahun dengan jenis pekerjaan karyawan administrasi Siloam Hospital Surabaya, mempunyai gangguan fleksibilitas lumbal diukur dengan Inclinometer dan modified schober test (MST), bersedia menjadi subjek penelitian sampai selesai yaitu dengan mengikuti program sebanyak 12 kali perlakuan 3 kali dalam 1 minggu dilakukan selama kurang lebih 4 minggu, menandatangi surat persetujuan (informed consent) kesediaan menjadi subjek, dan mampu mengerti intruksi yang diberikan. Kriteria eksklusi 
subjek penelitian adalah tidak sedang hamil, tidak setelah persalinan, riwayat trauma tulang belakang, keberatan mengikuti program penelitian ini. Kriteria drop out subjek penelitian adalah terjadi nyeri yang tidak tertahankan dan tidak datang mengikuti tes.

Kelompok peneltian ini terdapat 3 kelompok dengan masing-masing kelompok terdiri dari 10 orang. Perlakukan kelompok 1 (K1) menggunakan pelvic tilting exercise, kelompok 2 (K2) menggunakan knee to chest exercise, dan kelompok 3 (K3) menggunakan pelvic tilting exercise dan knee to chest exercise. Gerakan pada knee to chest exercise adalah posisi pasien tidur terlentang dengan kedua lutut fleksi dan kaki datar diatas bad atau lantai. Secara perlahan tarik lutut ke arah bahu dan pertahankan 510 detik diulang 8 kali. Sedangkan pada pelvic tilting exercise posisi pasien berbaring terlentang dengan posisi kedua lutut fleksi dan posisi kaki datar diatas matras Tekan atau luruskan punggung kearah matras dan dipertahankan selama 510 detik diulang 8 kali.

Seluruh subjek diukur dengan modified schober test (MST) dan Inclinometer sebelum dan setelah diberikan perlakuan (pretest-posttest). Metode penelitian menggunakan quasi eksperimental kuantitatif dengan rumus Federer. Variabel penelitian ini menggunakan variabel bebas dengan knee to chest exercise, dan pelvic tilting exercise, sedangkan variabel terikat yaitu fleksibilitas lumbal. Data dari hasil penelitian dianalisis secara statistik menggunakan program SPSS16.

Penelitian ini telah dilakukan kelaikan etik oleh Komisi Kelaikan Etik Penelitian Kesehatan (KKEPK) Fakultas Kedokteran Gigi Universitas Airlangga, dengan nomor kelaikan etik atau ethical clearance number

120/KKEPK.FKG/VII/2016.

\section{HASIL DAN PEMBAHASAN HASIL}

1. Hasil penelitian diperoleh data variabel kendali meliputi: usia, jenis kelamin dan indeks massa tubuh (IMT). Variabel tergantung berupa fleksibilitas lumbal yang diukur dengan modified schober test (MST) dan Inclinometer. Data hasil penelitian dianalisis secara statistic menggunakan program SPSS 16.

Tabel 1. Nilai rerata dan simpang baku karakteristik $\underline{\text { usia dan indeks masa tubuh (IMT) subjek }}$

\begin{tabular}{cccc}
\hline Variabel & $\mathrm{n}$ & $\begin{array}{c}\text { Rerata } \pm \\
\text { SD }\end{array}$ & $\mathrm{p}$ \\
\hline Usia (tahun) & 30 & $\begin{array}{c}31,00 \pm 2, \\
91\end{array}$ & 0,121 \\
\hline IMT $\left(\mathrm{kg} / \mathrm{m}^{2}\right)$ & 30 & $\begin{array}{c}22,50 \pm 2, \\
28\end{array}$ & $0,021^{*}$ \\
\hline
\end{tabular}

Keterangan: IMT (indeks masa tubuh), $\mathrm{n}$ (jumlah sampel), p (uji normalitas data karakteristik subjek dengan uji Shapiro-wilk, *signifikan bila $\mathrm{p}<0,05$ )

Berdasarkan data di atas dapat diketahui bahwa rerata dan simpangan baku usia subjek penelitian adalah $31,00 \pm 2,91$ tahun, dengan usia minimal 25 tahun dan maksimal 35 tahun, memiliki nilai $\mathrm{p}=0,121 \quad(\mathrm{p}>0,05)$, maka data usia semua kelompok berdistribusi normal. Nilai rerata simpangan baku indeks massa (IMT) tubuh subyek adalah $22,50 \pm 2,28 \mathrm{~kg} / \mathrm{m}^{2}$ dengan indeks massa tubuh minimal $16 \mathrm{~kg} / \mathrm{m}^{2}$ dan maksimal $25 \mathrm{~kg} / \mathrm{m}^{2}$, memiliki nilai $\mathrm{p}=0,021$ $(\mathrm{p}<0,05)$, maka data IMT semua kelompok tidak berdistribusi normal.

2. Hasil uji Homogenitas menggunakan uji Independen sampel t test dilakukan pada variabel usia dan IMT. Data pada variabel dikatakan memiliki varian yang homogen apa bila nilai uji $\mathrm{p}>0,05$. Uji homogenitas pada variabel usia dan IMT menunjukan bahwa data homogen. Hasil uji homogenitas dapat dilihat pada tabel 2 .

Tabel 2. Hasil uji homogenitas (p)

\begin{tabular}{cccc}
\hline Variabel & $\begin{array}{c}\text { Kelompok } \\
1 \& 3\end{array}$ & $\begin{array}{c}\text { Kelompok } \\
1 \& 2\end{array}$ & $\begin{array}{c}\text { Kelompok } \\
2 \& 3\end{array}$ \\
\hline Usia (tahun) & 0,146 & 0,105 & 0,127 \\
\hline
\end{tabular}




\begin{tabular}{llll} 
IMT $\left(\mathrm{kg} / \mathrm{m}^{2}\right)$ & 0,878 & $\mathrm{O}, 824$ & 0,09 \\
\hline
\end{tabular}

Keterangan: $* \mathrm{p}>0,05=$ homogen

3. Uji normalitas data untuk mengetahui data variabel berdistribusi normal atau tidak, maka perlu dilakukan uji normalitas menggunakan Shapiro-wilk. Nilai $\mathrm{p}>0,05$ menunjukkan distribusi data normal dan sebaliknya nilai $\mathrm{p}<0,05$ menunjukkan distribusi data tidak normal. Hasil uji normalitas data pengukuran fleksibilitas otot punggung bawah dengan pengukuran inclinometer dan modified schober test (MST) pretest dan posttest kelompok 1 pemberian pelvic tilting exercise, kelompok 2 pemberian knee to chest exercise, kelompok ke 3 latihan kombinasi pelvic exercise tilting dan latihan knee to chest exercise semua kelompok disajikan pada tabel 3

Tabel 3. Karakteristik variabel penelitian inclinometer dan modified schober test (MST) pada kelompok perlakuan

\begin{tabular}{|c|c|c|c|c|}
\hline & $\begin{array}{c}\text { Variabel } \\
\text { fleksibilitas }\end{array}$ & $\mathrm{n}$ & Rerata \pm SD & $\mathrm{p}$ \\
\hline \multirow{8}{*}{$\begin{array}{c}\text { pelvic } \\
\text { tilting } \\
\text { exercise }\end{array}$} & Inclinometer $\left(^{\circ}\right)$ & & & \\
\hline & Pretest & 10 & $4,20 \pm 1,47$ & $0,000 *$ \\
\hline & Posttest & 10 & $6,60 \pm 1,57$ & 0,141 \\
\hline & $\begin{array}{l}\Delta \text { inclinometer } \\
\quad(\mathrm{cm})\end{array}$ & 10 & $2,4 \pm 1,77$ & 0,256 \\
\hline & $\operatorname{MST}(\mathrm{cm})$ & & & \\
\hline & Pre test & 10 & $4,30 \pm 1,05$ & $0,002 *$ \\
\hline & Post test & 10 & $6,70 \pm 1,49$ & 0,854 \\
\hline & $\Delta \operatorname{MST}(\mathrm{cm})$ & 10 & $2,4 \pm 1,89$ & 0,287 \\
\hline \multirow{8}{*}{$\begin{array}{c}\text { knee to } \\
\text { chest } \\
\text { exercise }\end{array}$} & Inclinometer $\left({ }^{\circ}\right)$ & & & \\
\hline & Pretest & 10 & $4,5 \pm 1,58$ & $0,031 *$ \\
\hline & Posttest & 10 & $6,40 \pm 1,71$ & $0,008^{*}$ \\
\hline & $\begin{array}{l}\Delta \text { inclinometer } \\
\quad(\mathrm{cm})\end{array}$ & & $1,9 \pm 1,59$ & 0,145 \\
\hline & $\operatorname{MST}(\mathrm{cm})$ & & & \\
\hline & Pretest & 10 & $4,20 \pm 2,04$ & 0,362 \\
\hline & Posttest & 10 & $6,20 \pm 1,47$ & 0,158 \\
\hline & $\Delta \operatorname{MST}(\mathrm{cm})$ & & $2,00 \pm 1,41$ & 0,158 \\
\hline
\end{tabular}

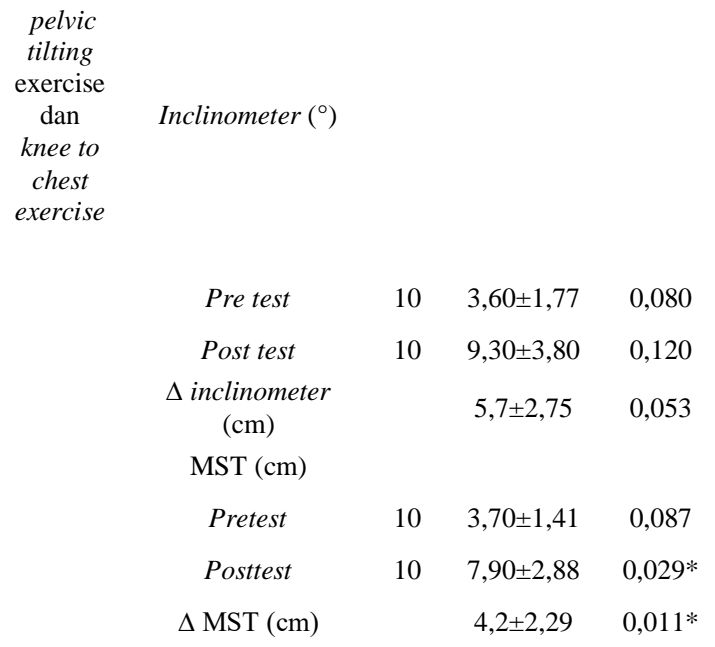

$\begin{array}{cccc}\text { Pre test } & 10 & 3,60 \pm 1,77 & 0,080 \\ \begin{array}{c}\text { Post test } \\ \begin{array}{c}\text { inclinometer } \\ (\mathrm{cm})\end{array}\end{array} & 10 & 9,30 \pm 3,80 & 0,120 \\ \text { MST (cm) } & & 5,7 \pm 2,75 & 0,053 \\ \text { Pretest } & 10 & 3,70 \pm 1,41 & 0,087 \\ \text { Posttest } & 10 & 7,90 \pm 2,88 & 0,029^{*} \\ \Delta \text { MST }(\mathrm{cm}) & & 4,2 \pm 2,29 & 0,011^{*}\end{array}$

Keterangan: $* \mathrm{p}<0,05$ menunjukkan data tidak berdistribusi normal

4. Analisis statistik variabel penelitian menggunakan uji Paired Samples $t$ Test karena beda data beda pre dan post dari pelvic tilting exercise data berdistribusi normal. Hal tersebut, bertujuan untuk menganalisis perbedaan pengaruh antara dua pengamatan yaitu antara sebelum dan setelah diberikan perlakuan. Sesuai dengan rumusan masalah, maka analisis perbedaan akan dilakukan pada fleksibilitas otot punggung bawah yang ditunjukkan dengan hasil pengukuran inclinometer dan MTS.

Table 4. Perbedan beda rerata pelvic tilting exercise pada pekerja administrasi pasca aktivitas duduk lama

\begin{tabular}{|c|c|c|c|}
\hline $\begin{array}{c}\text { Variabel } \\
\text { fleksibilitas }\end{array}$ & $\mathrm{n}$ & Rerata \pm SD & $\mathrm{p}$ \\
\hline Inclinometer $\left({ }^{\circ}\right)$ & 10 & $2,4 \pm 1,77$ & $0,002^{*}$ \\
\hline $\operatorname{MST}(\mathrm{cm})$ & 10 & $2,4 \pm 1,89$ & $0,003 *$ \\
\hline \multicolumn{4}{|c|}{ Keterangan: *signifikan bila $\mathrm{p}<0,05$} \\
\hline
\end{tabular}


menunjukkan hasil perbedaan yang bermakna $(\mathrm{p}=0,002)$ dan $(\mathrm{p}=0,003)$ pada fleksibilitas punggung bawah pada pelvic tilting exercise.

5. Hasil analisis perbedaan pengaruh fleksibilitas otot punggung bawah dengan inclinometer dan MST pre dan post knee to chest exercise pada pekerja administrasi pasca aktivitas duduk lama. Menganalisis perbedaan pengaruh fleksibilitas otot punggung bawah dengan inclinometer dan MST pre dan post knee to chest exercise. Analisis statistik pengukuran inclinometer dan MST menggunakan uji Paired Samples $t$ Test karena data beda pre dan post latihan knee to chest exercise berdistribusi normal

Table 5.5 Perbedan beda rerata latihan knee to chest exercise pada pekerja administrasi pasca aktivitas duduk lama.

\begin{tabular}{cccc}
\hline $\begin{array}{c}\text { Variabel } \\
\text { fleksibilitas }\end{array}$ & $\mathrm{n}$ & Rerata $\pm \mathrm{SD}$ & $\mathrm{p}$ \\
\hline Inclinometer $\left(^{\circ}\right)$ & 10 & $1,9 \pm 1,59$ & $0,004^{*}$ \\
\hline MST $(\mathrm{cm})$ & 10 & $2 \pm 1,41$ & $0,002^{*}$ \\
\hline
\end{tabular}

Keterangan: *signifikan bila $\mathrm{p}<0,05$

Pengukuran fleksibilitas otot punggung bawah dengan inclinometer dan MST menunjukkan hasil perbedaan yang bermakna $(\mathrm{p}=0,004$ dan $\mathrm{p}=0,002)$ pada fleksibilitas punggung bawah pada latihan knee to chest exercise.

6. Hasil uji normalitas data berdistribusi normal jika nilai $p>0,05$, sebaliknya data berdistribusi tidak normal jika nilai $\mathrm{p}<0,05$. Data pengukuran fleksibilitas otot punggung bawah pada kelompok pelvic tilting exercise dengan inclinometer maupun MST menunjukkan data tidak normal karena salah satu nilai $p<0,05$, sehingga uji beda menggunakan uji non parametrik. Data pengukuran fleksibilitas otot punggung bawah pada kelompok knee to chest exercise dengan inclinometer menunjukkan data tidak normal karena salah satu nilai $\mathrm{p}<0,05$, sehingga uji beda menggunakan uji non parametrik, sedangkan pengukuran dengan MST menunjukkan data normal, sehingga uji beda menggunakan uji parametrik. Data pengukuran fleksibilitas otot punggung bawah pada kelompok knee to chest exercise dan pelvic tilting exercise dengan inclinometer menunjukkan data normal, sehingga uji beda menggunakan uji parametrik, sedangkan pengukuran dengan MST menunjukkan data tidak normal, sehingga uji beda menggunakan uji non parametric.

Table 6. Perbedan beda rerata latihan kombinasi pelvic tilting exercise dan knee to chest exercise pada pekerja administrasi pasca aktivitas duduk lama.

\begin{tabular}{cccc}
\hline $\begin{array}{c}\text { Variabel } \\
\text { fleksibilitas }\end{array}$ & $\mathrm{n}$ & Rerata $\pm \mathrm{SD}$ & $\mathrm{p}$ \\
\hline Inclinometer $\left(^{\circ}\right)$ & 10 & $5,7 \pm 2,75$ & $0,005^{*}$ \\
\hline MST $(\mathrm{cm})$ & 10 & $4,2 \pm 2,29$ & $0,005^{*}$ \\
\hline
\end{tabular}

Keterangan: $* \mathrm{p}<0,05$ artinya terdapat perbedaan pengaruh

Pengukuran fleksibilitas otot punggung bawah dengan inclinometer dan MST menunjukkan hasil perbedaan yang bermakna $(\mathrm{p}=0,005)$ dan $(\mathrm{p}=0,005)$ pada fleksibilitas punggung bawah pada latihan kombinasi pelvic tilting exercise dan knee to chest exercise

7. Hasil analisis perbedaan efek latihan kombinasi lebih baik dari latihan tunggal. Analisis ini dilakukan karena ketiga latihan di atas memberikan perbedaan yang signifikan pasca perlakuan, maka diperlukan melakukan uji analisis untuk membedakan kelompok perlakuan yang terbaik. Dilakukan uji analisis parametrik untuk 
membedakan perubahan inclinometer pada ketiga kelompok dengan menggunakan uji Anova. Dilakukan uji analisis non parametrik untuk membedakan perubahan MST pada ketiga kelompok dengan menggunakan uji Kruskal Wallis yang dilanjutkan dengan uji Mann Whitney

Fleksibilitas otot punggung bawah dengan pengukuran inclinometer $\mathrm{p}=0,001$ dan pengukuran menggunakan MST $\mathrm{p}=0,03$, maka nilai $\mathrm{p}<0,05$ yang artinya ada perbedaan dari ketiga kelompok tersebut. Selanjutnya diuji kelompok mana yang paling baik menggunakan uji beda antar kelompok tidak berpasangan.

Tabel 7 Perbandingan pengukuran fleksibilitas antar kelompok dengan inclinometer dan MST

\begin{tabular}{|c|c|c|c|c|c|}
\hline $\begin{array}{c}\text { Variabel } \\
\text { fleksibilitas }\end{array}$ & $\mathrm{n}$ & K1 & $\mathrm{K} 2$ & K3 & $\mathrm{p}$ \\
\hline \multirow[t]{3}{*}{$\begin{array}{c}\text { Inclinometer } \\
\left({ }^{\circ}\right)\end{array}$} & 30 & $\begin{array}{c}2,4 \pm 1 \\
77\end{array}$ & $1,9 \pm 1,59$ & $5,7 \pm 2,75$ & $\begin{array}{l}\mathrm{K} 1-\mathrm{K} 2: \\
0,516 \text { (a) }\end{array}$ \\
\hline & & & & & $\begin{array}{l}\mathrm{K} 1-\mathrm{K} 3: \\
0,011 *(\mathrm{a})\end{array}$ \\
\hline & & & & & $\begin{array}{l}\text { K2-K3 : } \\
0,003 *(a)\end{array}$ \\
\hline \multirow[t]{2}{*}{$\operatorname{MST}(\mathrm{cm})$} & 30 & $\begin{array}{c}2,4 \pm 1 \\
89\end{array}$ & $2 \pm 1,41$ & $4,2 \pm 2,29$ & $\begin{array}{l}\text { K1-K2 : } \\
0,600 \text { (b) }\end{array}$ \\
\hline & & & & & $\begin{array}{l}\text { K1-K3 : } \\
0,056 \text { (b) } \\
\text { K2-K3 : } \\
0,014 *(b)\end{array}$ \\
\hline \multicolumn{6}{|c|}{$\begin{array}{l}\text { Keterangan: MST (modified schober test), K1 } \\
\text { (kelompok 1), K2 (kelompok } 2), \mathrm{K} 3(\mathrm{kelompok} 3), * \\
\text { signifikan bila } \mathrm{p}<0,05(\mathrm{a}=\text { Independen sampel t test }) \\
(\mathrm{b}=\text { Mann Whitney) }\end{array}$} \\
\hline
\end{tabular}

7.1 Fleksibilitas otot punggung bawah antara kelompok 1 dan 2 diukur dengan inclinometer dihasilkan nilai $\mathrm{p}=0,516$, artinya $\mathrm{p}>0,05$, maka antara kelompok 1 dan 2 tidak terdapat perbedaan bermakna.

7.2 Fleksibilitas otot punggung bawah antara kelompok 1 dan 3 diukur dengan inclinometer dihasilkan nilai $\mathrm{p}=0,011$ artinya $\mathrm{p}<0,05$, maka antara kelompok 1 dan 3 terdapat perbedaan bermakna.

7.3 Fleksibilitas otot punggung bawah antara kelompok 2 dan 3 diukur dengan inclinometer dihasilkan nilai $\mathrm{p}=0,003$, artinya $\mathrm{p}<0,05$, maka antara kelompok 2 dan 3 terdapat perbedaan bermakna.
7.4 Fleksibilitas otot punggung bawah antara kelompok 1 dan 2 diukur dengan MST dihasilkan nilai $\mathrm{p}=0,600$, artinya $\mathrm{p}>0,05$, maka antara kelompok 1 dan 2 tidak terdapat perbedaan bermakna.

7.5 Fleksibilitas otot punggung bawah antara kelompok 1 dan 3 diukur dengan MST dihasilkan nilai $\mathrm{p}=0,056$ artinya $\mathrm{p}>0,05$, maka antara kelompok 1 dan 3 tidak terdapat perbedaan bermakna.

7.6 Fleksibilitas otot punggung bawah antara kelompok 2 dan 3 diukur dengan MST dihasilkan nilai $\mathrm{p}=0,014$ artinya $\mathrm{p}<0,05$, maka antara kelompok 2 dan 3 terdapat perbedaan bermakna.

Analisis data telah menunjukkan bahwa terdapat perbedaan dalam peningkatan fleksibilitas punggung bawah baik yang diukur dengan inclinometer maupun MST. Perbedaan bermakna ditemukan pada kelompok pelvic tilting exercise (K1), knee to chest exercise (K2) dan kelompok kombinasi knee to chest exercise dan pelvic tilting exercise (K3).

\section{PEMBAHASAN}

Analisis hasil data dari perbadingan fleksibilitas otot punggung bawah antara sebelum dan setelah perlakuan pelvic tilting exercise dengan dosis 8 kali pengulangan dilakukan 3 kali seminggu selama 4 minggu dengan menggunakan MST dan Inclinometer. Uji hipotesis perbedaan fleksibilitas otot punggung bawah sebelum dan setelah pelvic tilting exercise menunjukkan adanya perbedaan bermakna setelah pelvic tilting exercise. Hal tersebut membuktikan bahwa pelvic tilting exercise dapat meningkatkan fleksibilitas otot punggung bawah yang diukur dengan MST dan Inclinometer.

Gerakan pelvic tilting exercise akan mengkontraksikan otot-otot abdomen dan pelvis sehingga akan merelaksasikan otot lumbal yang di ikuti perbaikan postur (Neuman, 2010). Otot pelvis dan abdomen yang berkontraksi dapat mengurangi spasme otot lumbal, memperbaiki postur dan menyebabkan keseimbangan otot, sehingga fleksibilitas otot punggung bawah akan bertambah. Hal tersebut sejalan dengan penelitian Koumantakis GA et al, 2005 yang membuktikan bahwa pasien dengan kondisi NPB lebih bermanfaat dan menguntungkan jika 
sejak awal diberikan pelvic tilting exercise secara berulang untuk mencegah ketidakstabilan dari otot-otot trunk yang dibandingkan dengan diberikan program general exercises.

Analisis hasil data dari perbadingan fleksibilitas otot punggung bawah antara sebelum dan setelah perlakuan knee to chest exercise dengan dosis 8 kali pengulangan dilakukan 3 kali seminggu selama 4 minggu dengan menggunakan MST dan Inclinometer. Uji hipotesis perbedaan fleksibilitas otot punggung bawah sebelum dan setelah knee to chest exercise menunjukkan adanya perbedaan bermakna setelah knee to chest exercise. Hal tersebut membuktikan bahwa knee to chest exercise dapat meningkatkan fleksibilitas otot punggung bawah baik diukur dengan MST dan Inclinometer. Seperti yang sudah dijelaskan di atas bahwa fleksibilitas penting untuk memudahkan tubuh dalam melakukan suatu gerakan dengan nyaman dan bermanfaat untuk mencegah cedera maupun memperbaiki postur (Catherin, 2008)

Gerakan knee to chest exercise adalah sebuah program latihan dengan tujuan untuk mengurangi tekanan oleh beban tubuh pada sendi facet dan meregangkan otot dan fascia di daerah dorsolumbal, serta bermanfaat mengkoreksi postur tubuh yang salah. Latihan ini juga dapat meningkatkan stabilitas lumbal karena secara aktif melatih otot-otot abdominal dengan meningkatkan tekanan abdominal yang mendorong kolumna vertebralis ke arah belakang. Latihan ini membantu mengurangi hiperlordosis lumbal akibat regangan pada otototot lumbal, sehingga spasme otot berkurang dan terjadi keseimbangan kerja antara otot abdomen dan lumbal yang diikuti peningkatan fleksibilitas otot (Hills, 2006). Hal tersebut sejalan dengan penelitian yang di kemukakan oleh Kurniawan hadi pada tahun 2004 yang membuktikan bahwa pasien dengan kondisi nyeri punggung bawah mekanik jika diberikan latihan knee to chest exercise akan menyebabkan efek stretching pada otot ekstensor punggung yang tegang sehingga akan memperbaiki mobilitas lumbal dan aktifitas fungsional pasien tersebut (Hadi, 2004).

Analisis hasil data dari perbadingan fleksibilitas otot punggung bawah antara sebelum dan setelah perlakuan knee to chest exercise dan pelvic tilting exercise dengan dosis 8 kali pengulangan dilakukan 3 kali seminggu selama 4 minggu dengan menggunakan MST dan Inclinometer. Uji hipotesis perbedaan fleksibilitas otot punggung bawah sebelum dan setelah latihan kombinasi knee to chest exercise dan pelvic tilting exercise menunjukkan adanya perbedaan bermakna setelah latihan kombinasi knee to chest dan pelvic tilting. Hal tersebut membuktikan bahwa kedua latihan tersebut dapat meningkatkan fleksibilitas otot punggung bawah baik diukur dengan MST dan Inclinometer

Menurut Dachlan tahun 2009 dalam penelitiannya disebutkan bahwa latihan merupakan program rehabilitasi guna meningkatkan kekuatan otot punggung dan abdomen, seperti halnya latihan stretching untuk meningkatkan fleksibilitas otot punggung bawah, termasuk latihan ini adalah kombinasi latihan knee to chest exercise dan pelvic tilting exercise (Dachlan, 2009).

Analisis hasil data seluruh kelompok dengan masing-masing perlakuan, terdapat perbedaan antara sebelum dan sesudah latihan. Tetapi setelah dilakukan uji beda Inclinometer menggunakan uji Anova dan MST menggunakan uji Kruskal wallis yang dilanjutkan dengan uji Mann-whitney untuk mengetahui perbedaan antar kelompok menunjukan bahwa hasil yang paling signifikan dalam peningkatan fleksibilitas punggung bawah yang di ukur dengan Inclinometer dan MST adalah perbedaan antara kelompok 1 (pelvic tilting exercise), kelompok 2 (knee to chest exercise), dan kelompok 3 (kombinasi knee to chest exercise dan pelvic tilting exercise). Untuk mengetahui kelompok mana yang paling berpengaruh antara kelompok 1, 2 dan 3 maka Perbedaan yang bermakna dapat dilihat dari nilai delta pada masing-masing kelompok yaitu kelompok 3 lebih besar dari kelompok 1 dan 2 sehingga latihan gabungan knee to chest exercise dan pelvic tilting exercise lebih baik dibanding latihan tunggal.

Hal tersebut membuktikan bahwa latihan kombinasi lebih memiliki daya regang yang cukup besar dan berguna untuk koreksi postur pada lumbal dan pelvic sehingga lebih dapat meningkatkan fleksibilitas punggung bawah (Kisner, 2011; Muscolino 2015).

\section{KESIMPULAN}

Berdasarkan analisis data dan pembahasan dari penelitian yang telah dilakukan, maka dapat disimpulkan bahwa: 
1. Terdapat pengaruh pelvic tilting exercise pada fleksibilitas otot punggung bawah pada pekerja administrasi akibat aktivitas dengan posisi duduk lama.

2. Terdapat pengaruh knee to chest exercise pada fleksibilitas otot punggung bawah pada pekerja administrasi akibat aktivitas dengan posisi duduk lama.

3. Terdapat pengaruh knee to chest exercise dan pelvic tilting exercise pada fleksibilitas otot punggung bawah pada pekerja administrasi akibat aktivitas dengan posisi duduk lama

\section{DAFTAR PUSTAKA}

AAHPERD, 1999. Physical Education for Lifelong Fitness: The Physical Best Teacher's Guide. Human Kinetics

Baehr, M., Frotscher M, 2010. Diagnosis Topik Neurologi DUUS, Anatomi, Fisiologi, Tanda, Gejala. Ed. 4. Penerbit Buku Kedokteran EGC. Jakarta

Cherkin, D. C, 2001. Massage techniques effective in reducing chronic back pain. Group Health Cooperative of Puget Sound Center for Health Studies. Seattle. Washington. Originally published in Archives of Internal Medicine. April 23, Vol. 161, No.8. (cited 2011 september). from http www.massagetherapylaketahoe.com/m assagetechniquesresearch.html

Dachlan, M., Leo, 2009. Pengaruh Back Exercise Pada Nyeri Punggung Bawah. Magister kedokteran Keluarga Minat Utama Pendidikan Profesi Kesehatan Universitas Sebelas Maret. Surakarta

Kusuma, H., dan Setiowati, A., 2015. Pengaruh William Flexion Exercise Dalam Meningkatan Lingkup Gerak Sendi Pada Bagian Lumbal Pada Penderita Low Back Pain. Journal of Sport Sciences and Fitness http://journal.unnes.ac.id/sju/index.php /jssf

Hills, E.C., 2006. Mechanical Low Back Pain. Retrieved: 10/12/2013, Available from: http://www.emedicine.com

Kisner, C. 2011. Therapeutic Exercise Foundation and Techniques. Sixth edition. Philadelphia: F.A Davis Company

Koumantakis, G.A., Watson, P. J., and Oldham, J. A. 2005. Trunk Muscle Stabilization Training Plus General Exercise Versus General Exercise Only: Randomized Controlled Trial of Patients with Recurrent Low Back Pain. London: Phys Ther. vol. 85. Hal 209 225.

MacDermid et al. 2014. The Reliability and Validity of the Computerized Double Inclinometer in Measuring Lumbar Mobility. School of rehabilitation science, McMaster University, Hamilton, Ontario, Canada.

Muscolino. E. Joseph., 2015. Body Mechanics, A Few Simple Stretches for the Low Back. Manual Therapists at the AMTA 2015 National Convention.

Purba, Jan., S., dan Rumawas, Ashwin, 2006. Nyeri Punggung Bawah: Studi Epidemiologi, Patofisiologi dan Penanggulangan. Di akses 9 agustus 2016 http://ilib.ugm.ac.id/jurnal/detail.php?dataId= 4707

Sidharta P., 2010. Anamnesa Kasus Nyeri di Ekstremitas Dan Pinggang, Sakit Pinggang. In: Tatas Pemeriksaan Klinis Dalam Neurologi. Jakarta: Pustaka Universitas, 2010: 64-75.

Weitz. 2005. Duduk Statis Sebagai Faktor Risik Terjadinya Nyeri Punggung Bawah Pada Pekerja Perempuan, vol.24 no.2. Universitas Indonesia. 
William, 2006. Effect Flexibility on Sport Injury. 3 Februari 2013. Available from: URL:hhpt/www.pubmed.com. 